\title{
Impact of liver fibrosis on prognosis following liver resection for hepatitis B-associated hepatocellular carcinoma
}

\author{
Q Wang ${ }^{1}$, M I Fiel ${ }^{2}$, S Blank ${ }^{1}$, W Luan ${ }^{1}, \mathrm{H} \mathrm{Kadri}^{1}, \mathrm{~K} \mathrm{~W} \mathrm{Kim}{ }^{1}$, F Manizate ${ }^{1}$, A G Rosenblatt ${ }^{1}$, D M Labow ${ }^{1}$, \\ M E Schwartz ${ }^{1}$ and S P Hiotis ${ }^{*}, 1$ \\ ${ }^{1}$ Department of Surgery, Mount Sinai School of Medicine, New York, NY 10029, USA and ${ }^{2}$ Department of Pathology, Mount Sinai \\ School of Medicine, New York, NY 10029, USA
}

Background: This study aims to evaluate the impact of liver fibrosis severity on prognosis following liver resection among HBV-HCC patients.

Methods: Data were extracted from a prospective database of 189 HBV-HCC patients treated at Mount Sinai between 1995 and 2008. Fibrosis staging of each surgical resection specimen using the modified Ishak method was performed by a single liver pathologist.

Results: A wide range of Ishak fibrosis stage was observed among this patient population, with $29 \%$ having established cirrhosis (Ishak stage 6). Ishak stage 6 was independently associated with poor overall and recurrence-free survival. In patients with Ishak stage 1-5, Ishak stage did not affect survival; rather, tumour size was associated with poor overall survival, and tumour size, histologic activity index and serum AFP $>20 \mathrm{ng} \mathrm{ml}^{-1}$ were associated with poor recurrence-free survival. In patients with Ishak stage 6, poorly differentiated histology and tumour size were associated with poor overall survival, and tumour size was associated with poor recurrence-free survival.

Conclusion: HBV-HCC develops with varying degrees of underlying liver fibrosis; however, progressive liver fibrosis does not affect the outcomes following resection until cirrhosis is reached. Established cirrhosis, as defined histologically by Ishak stage 6, is an independent predictor of poor overall and recurrence-free survival among these patients.

Patients with chronic hepatitis B virus (HBV) liver disease are subject to an increased lifetime risk of hepatocellular carcinoma (HCC). In the majority of cases, HCC develops in the setting of bridging fibrosis or cirrhosis, a progressive process in which chronic necroinflammation and hepatocellular regeneration result in the production of reactive oxygen species, chromosomal mutations and, eventually, malignant transformation of proliferating hepatocytes (Lok and McMahon, 2009; El-Serag, 2011; de Lope et al, 2012; European Association for the Study of the L, European Organisation for R, Treatment of C, 2012). However, although the risk of HCC is highest among those with severe chronic inflammatory damage and cirrhosis, a certain proportion of HCC arises within non-cirrhotic liver (Bralet et al, 2000; Liu et al, 2009; Tretiakova et al, 2009, 2010; Trevisani et al, 2010). The reported percentage of non-cirrhotic HCC ranges from 7 to $54 \%$, depending on the demographic areas, the underlying aetiology and the materials studied (liver biopsies, autopsies or resected liver) (Bralet et al, 2000; Liu et al, 2009; Tretiakova et al, 2009, 2010; Trevisani et al, 2010). A higher prevalence of HBV-HCC arising within non-cirrhotic liver has been noted (Bralet et al, 2000; Yang et al, 2011).

HCC arising within a non-cirrhotic liver is a poorly understood entity, in regard to associated histopathologic features and molecular events that regulate tumour progression. Although 
some studies separate patients into cirrhotic and non-cirrhotic groups, the non-neoplastic liver of non-cirrhotic HBV patients usually harbours some element of abnormality and is rarely 'normal'. In particular, the degree of fibrosis in the non-neoplastic liver may vary significantly among these patients, and is most accurately assessed using a sophisticated staging system such as the Ishak method. The non-cirrhotic chronic HBV liver harbouring HCC may range from minimally to severely fibrotic, with marked portal-to-portal and portal-to-central bridging fibrosis (Goodman, 2007), in addition to varying degrees of concomitant necroinflammatory change. This study examines the cancer-specific outcomes among groups with accurately staged liver fibrosis upon initial HCC diagnosis. A better understanding of HCC arising in non-cirrhotic chronic HBV patients is essential for the development of optimal algorithms for screening and treatment.

\section{MATERIALS AND METHODS}

Patients, histopathologic assessment and follow-up. This study includes all HBV-HCC patients who underwent surgical resection at Mount Sinai Medical Center in New York, NY, USA, between 1995 and 2008. The study protocol conformed to the ethical guidelines of the 1975 Declaration of Helsinki as reflected by the appropriate institutional review committee. Institutional review board approval of all aspects of the research study was obtained prior to study initiation.

All patients were assessed pre-operatively by axial imaging (three-phase computerised tomography (CT) with intravenous contrast, or multi-phase magnetic resonance imaging (MRI) with intravenous contrast). Liver resection was performed in patients with surgically resectable disease and normal synthetic liver function as assessed by normal serum total bilirubin, albumin and INR. Patients with portal hypertension as evidenced by a platelet count $<100 \times 10^{3} \mu^{-1}$, peri-oesophageal or peri-splenic varcies on axial imaging, or portal-systemic venous pressure gradient $\geqslant 10 \mathrm{~mm} \mathrm{Hg}$ were excluded from liver resection. Only Child-Pugh A cirrhotics were included in this cohort, and patients with clinical evidence of Child-Pugh B-C cirrhosis were excluded. Patients who underwent liver transplantation were not included in this analysis.

Liver resection specimens were assessed by a single liver pathologist, blinded to all patient demographics and clinical outcomes. The degree of hepatic fibrosis in non-neoplastic liver tissue was scored using the modified Ishak method (stage 0-6) as follows: stage 0 (normal liver); stage 1 (fibrosis expansion of a few portal tracts); stage 2 (fibrosis of all portal tracts); stage 3 (fibrous expansion of most portal areas with occasional portal-to-portal bridging); stage 4 (fibrous expansion of portal areas with marked bridging); stage 5 (marked bridging with occasional nodules); stage 6 (established cirrhosis with the tissue entirely composed of nodules (Ishak et al, 1995; Brunt, 2000; Goodman, 2007). Examples of resected liver specimens and corresponding histological photomicrographs for each Ishak fibrosis stage are included (Figure 1). For every resection specimen, a minimum of two sections were taken from the uninvolved liver distant from the tumour mass, and all H\&E and trichrome-stained slides (at least two H\&E stainings and two trichromes per case) from the nontumour areas were evaluated to arrive at the final Ishak fibrosis score. Histologic activity index (HAI) representing necroinflammatory grade and tumour characteristics, including tumour differentiation and vascular invasion, were assessed by the same dedicated pathologist specifically for the intended purpose of this study. Tumour number, largest tumour diameter and surgical margin were determined from standard clinical pathology report, rather than re-review of specimens. Information on biochemical markers was obtained from the medical record.
All patients were followed every 3 months in the first postoperative year, every 4 months in the second postoperative year and every 6 months thereafter. Imaging with CT or MRI was obtained for each patient on every follow-up visit, along with blood work including AFP as an adjunct only to imaging findings. Tumour recurrence was diagnosed on the basis of imaging findings on the follow-up CT or MRI. For patients in our cohort who developed HCC recurrence, 41\% subsequently received non-operative therapy (RFA or TACE) for local control, 18\% underwent secondary liver resection and none received salvage liver transplantation.

Statistical analysis. All statistical analyses were performed using SPSS 19 (IBM, Armonk, NY, USA) and SAS 9.2 software (SAS Institute, Inc., Cary, NC, USA). Categorical variables were compared using Fisher's exact test, and continuous variables were compared using two-tailed $t$-tests or non-parametric MannWhitney $U$-tests. The correlation between variables was evaluated using the Pearson's or Spearman's correlation coefficients. The survival rates from the date of initial visit to the date of death or the date of last follow-up, as well as the recurrence-free survival, defined as the time from surgery to the time of recurrence, death or date of last follow-up, was calculated using the Kaplan-Meier method. Patients with follow-up less than 60 months and with no death or recurrence were entered as censored data. Early recurrence was defined as recurrence events that occurred within 24 months of surgical resection. Clinically relevant variables were compared using log-rank tests and Wilcoxon tests for categorical variables, and univariate Cox proportional hazard regression for continuous variables.

Multivariate Cox proportional hazard regression was used to obtain hazard ratios and 95\% confidence intervals associated with overall survival as well as recurrence-free survival. The final models were determined by placing all variables with $P<0.1$ from the univariate analysis into a preliminary multivariate Cox proportional hazard regression model and using a forward stepwise variable selection process. The proportionality of hazards was tested in the regression model, both for individual variables and in the final models.

\section{RESULTS}

Clinical-pathologic characteristics of the patient cohort. A total of $189 \mathrm{HBV}-\mathrm{HCC}$ patients were included in this study (Table 1). The mean age of patients was 56 years. The majority of patients were male (80\%) and of Asian race (67\%). Mean tumour size upon diagnosis was $6.3 \pm 4.5 \mathrm{~cm}$. Median follow-up of survivors included in survival analyses was 52 months.

An Ishak fibrosis stage 0 (normal liver) was never observed in these patients, but a wide range of underlying liver fibrosis from stages 1 to 6 was observed (Table 1, Figure 1). A negative correlation was observed between tumour diameter and Ishak fibrosis stage $(r=-0.17, P=0.02)$, with larger tumour size seen among patients with less-severe liver fibrosis. The HAI positively correlated with Ishak stage $(r=0.15, P=0.04)$. In addition, Ishak stage negatively correlated with circulating platelet counts and albumin $(r=-0.22, P=0.004$ and $r=-0.15, P=0.050$, respectively), whereas positively correlating with serum ALT and bilirubin ( $r=0.30, P<0.001$ and $r=0.15, P=0.049$, respectively).

We analysed patients according to the presence or absence of established cirrhosis (Ishak stage 6 vs Ishak stage 1-5) upon initial HCC diagnosis (Supplementary Table 1). Tumour size was smaller among cirrhotic vs non-cirrhotic patients $(5.4 \pm 3.4 v s 6.8 \pm 4.9 \mathrm{~cm}$, $P=0.03)$. In addition, cirrhotic patients had lower platelet counts, higher serum ALT and higher serum total bilirubin concentrations. Actuarial 5-year survival was significantly worse for cirrhotic vs non-cirrhotic patients (50 vs 73\% 5-year survival, $P=0.01$ ). The 

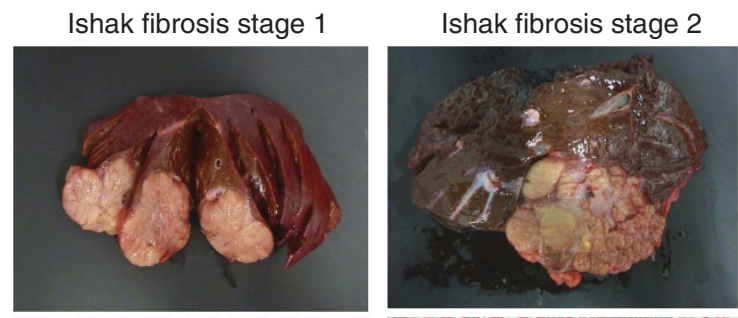

Ishak fibrosis stage 3
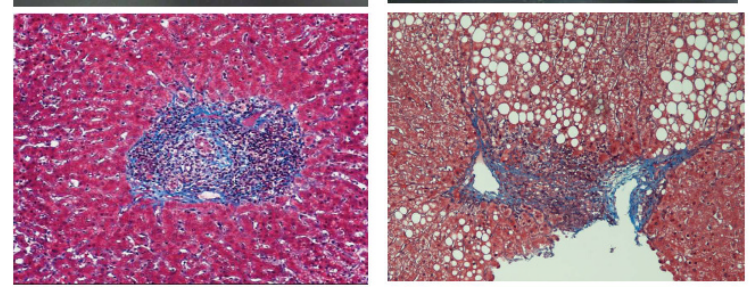

Ishak fibrosis stage 5
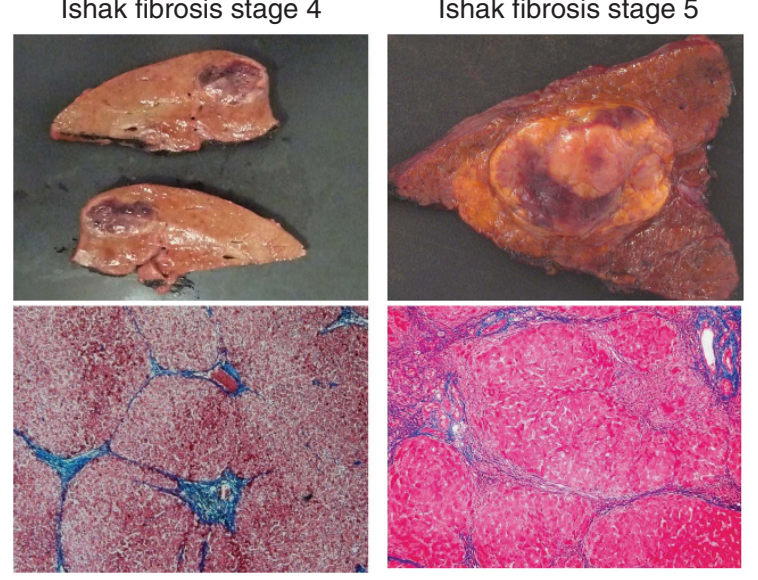

Ishak fibrosis stage 6
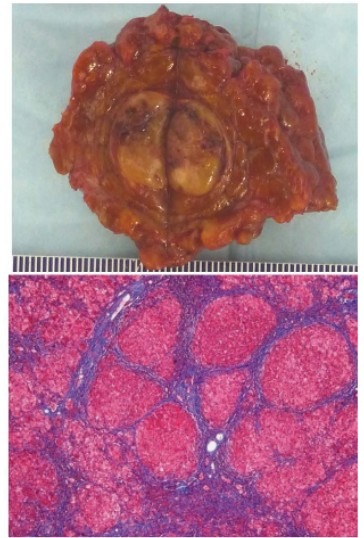

Figure 1. Representative HBV-HCC liver resection specimens and corresponding histological micrographs of the non-neoplastic liver with Ishak fibrosis stages from 1 to 6 . Liver histological slides from resection specimens were prepared using the Masson trichrome stain, and liver fibrosis was scored using the modified Ishak method.

majority of deaths were associated with HCC recurrence (47 out of $64,73 \%$ ), and this ratio was similar in cirrhotic (19 out of 27, $70 \%) v s$ non-cirrhotic patients (28 out of $37,75 \%)(P=0.78)$. Early tumour recurrence was more frequent among cirrhotic $v s$ non-cirrhotic patients (50 vs 36\% 2-year tumour recurrence, $P=0.07)$.

Ishak stage 6 was associated with poor overall and recurrencefree survival. Male sex, Asian race, poorly differentiated histology, macroscopic or microscopic vascular invasion, tumour size, surgical resection margin, anatomic resection, serum

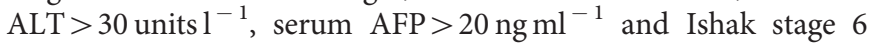
were associated with poor overall survival in the univariate analysis (Table 2, Figure 2A and B). However, among patients with Ishak stage $1-5$, progressive increase in Ishak fibrosis stage was not associated with poor overall survival (Figure 2A). Compared with patients with Ishak stage $1-4$, Ishak stage 5 was not different in overall survival rate $(P=0.26)$, whereas Ishak stage 6 was significantly associated with poor overall survival $(P=0.005)$.

Variables found significant in univariate analysis at a $P=0.1$ level were put into a preliminary multivariate Cox regression analysis. Based on a forward stepwise selection process, tumour size, resection margin, serum AFP $>20 \mathrm{ng} \mathrm{ml}^{-1}$ and Ishak stage 6 were all found to be independently associated with poor overall survival (Table 2). Compared with Ishak stage 1-4, Ishak stage 6 had a higher hazard ratio (HR) for mortality (HR: 6.33 (2.52-15.94), $P<0.001)$, whereas Ishak stage 5 did not (HR: 1.84 $(0.64-5.30), P=0.26)$.
In univariate analysis, male sex, poorly differentiated histology, macroscopic vascular invasion, tumour size, anatomic resection,

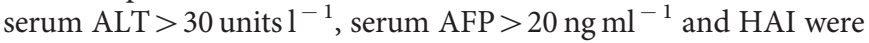
associated with poor recurrence-free survival, and Ishak stage 6 compared with Ishak stage $1-5$ had a marginally significant impact on recurrence-free survival (Table 2, Figure 2C, $P=0.05$ ). Multivariate analysis indicated that poorly differentiated histology, macroscopic vascular invasion, tumour size, HAI and Ishak stage 6 were independently associated with poor recurrence-free survival. Similar to the findings for overall survival, compared with Ishak stage 1-4, Ishak 5 was not different in recurrence-free survival (HR: $0.77(0.42-1.39), P=0.39)$, whereas Ishak stage 6 was associated with poor recurrence-free survival (HR: 1.71 (1.04-2.83), $P=0.03$ ).

Seventy-five of the 102 recurrence events occurred with 24 months (Table 1). Factors associated with early recurrence rate were also analysed (Supplementary Table 2). Multivariate analysis indicated that macroscopic vascular invasion, tumour size, HAI and Ishak stage 6 were independently associated with higher early recurrence rate. Ishak stage 5 was not different from Ishak stage $1-4$ in early recurrence rate by univariate $(P=0.58)$ or multivariate analysis (HR: 0.91(0.38-2.20), $P=0.84$ ).

One hundred and forty-one patients had documented perioperative anti-viral therapy. The proportion of different Ishak stages among these 141 patients was similar to the entire patient cohort (Supplementary Table 3). Among these 141 patients, factors associated with poor overall survival, recurrence-free survival and early recurrence rate were similar to those identified in the entire 
Table 1. Characterisation of HBV-HCC patients with varying degrees of underlying liver fibrosis

\section{Ishak stage}

\begin{tabular}{|c|c|c|c|c|c|c|c|}
\hline & All & 1 & 2 & 3 & 4 & 5 & 6 \\
\hline & 189 & 10 & 35 & 17 & 30 & 43 & 54 \\
\hline & $100 \%$ & $5 \%$ & $18 \%$ & $9 \%$ & $16 \%$ & $23 \%$ & $29 \%$ \\
\hline \multicolumn{8}{|l|}{ Age } \\
\hline $\begin{array}{l}\text { Mean } \pm \text { s.d. } \\
\text { Range }\end{array}$ & $\begin{array}{c}56 \pm 12 \\
22-83\end{array}$ & $\begin{array}{c}53 \pm 14 \\
34-79\end{array}$ & $\begin{array}{c}55 \pm 13 \\
22-82\end{array}$ & $\begin{array}{c}55 \pm 11 \\
37-68\end{array}$ & $\begin{array}{c}58 \pm 12 \\
29-75\end{array}$ & $\begin{array}{c}59 \pm 12 \\
38-83\end{array}$ & $\begin{array}{c}55 \pm 11 \\
31-77\end{array}$ \\
\hline \multicolumn{8}{|l|}{ Gender } \\
\hline $\begin{array}{l}\text { Male } \\
\% \text { male } \\
\text { Female } \\
\% \text { female }\end{array}$ & $\begin{array}{c}151 \\
80 \\
38 \\
20\end{array}$ & $\begin{array}{c}7 \\
70 \\
3 \\
30\end{array}$ & $\begin{array}{l}25 \\
71 \\
10 \\
29\end{array}$ & $\begin{array}{c}13 \\
77 \\
4 \\
23\end{array}$ & $\begin{array}{c}25 \\
83 \\
5 \\
17\end{array}$ & $\begin{array}{c}34 \\
79 \\
9 \\
21\end{array}$ & $\begin{array}{c}47 \\
87 \\
7 \\
13\end{array}$ \\
\hline
\end{tabular}

\section{Race}

Asian

Caucasian

African/American

Hispanic

Other/unknown

\begin{tabular}{c|c|c}
\hline 127 & 5 & \\
15 & 0 & \\
15 & 1 & \\
3 & 0 & \\
29 & 4 &
\end{tabular}

\begin{tabular}{l|l}
28 & \\
2 & \\
1 & \\
0 & \\
4 &
\end{tabular}

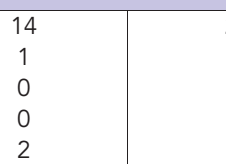

\section{Tumour size $(\mathrm{cm})$}

\begin{tabular}{|c|c|c|c|c|c|c|c|}
\hline $\begin{array}{l}\text { Mean } \pm \text { s.d. } \\
\leqslant 5\end{array}$ & $\begin{array}{c}6.3 \pm 4.5 \\
91\end{array}$ & $\begin{array}{c}7.0 \pm 33 \\
3\end{array}$ & $\begin{array}{c}7.2 \pm 5.7 \\
17\end{array}$ & $\begin{array}{c}8.3 \pm 6.1 \\
6\end{array}$ & $\begin{array}{c}6.5 \pm 4.8 \\
13\end{array}$ & $\begin{array}{c}5.9 \pm 4.0 \\
22\end{array}$ & $\begin{array}{c}5.4 \pm 3.4 \\
30\end{array}$ \\
\hline 5-10 & 58 & 4 & 7 & 5 & 9 & 16 & 17 \\
\hline$\geqslant 10$ & 31 & 1 & 9 & 5 & 6 & 5 & 5 \\
\hline
\end{tabular}

\section{Tumour number}

\begin{tabular}{|l|c|c|c|c|c|c|c|c|c|}
\hline Single & 150 & 7 & 28 & 15 & 22 & 44 \\
Multiple & 31 & 1 & 5 & 9 & 9 & 9
\end{tabular}

\section{Tumour differentiation}

\begin{tabular}{|c|c|c|c|c|c|c|c|}
\hline Well & 28 & 0 & 7 & 2 & 8 & 5 & 6 \\
\hline Moderate & 85 & 6 & 17 & 7 & 10 & 21 & 24 \\
\hline Poor & 64 & 4 & 8 & 7 & 11 & 12 & 22 \\
\hline
\end{tabular}

\section{Vascular invasion}

\begin{tabular}{|c|c|c|c|c|c|c|c|}
\hline None & 18 & 0 & 4 & 1 & 2 & 4 & 7 \\
\hline Microscopic & 143 & 9 & 27 & 13 & 25 & 32 & 37 \\
\hline Macroscopic & 12 & 1 & 1 & 1 & 2 & 1 & 6 \\
\hline
\end{tabular}

\section{Resection margin $(\mathrm{cm})$}

\begin{tabular}{|c|c|c|c|c|c|c|c|}
\hline Mean \pm s.d. & $1.1 \pm 1.0$ & $0.8 \pm 0.9$ & $1.2 \pm 1.2$ & $1.2 \pm 1.1$ & $0.9 \pm 0.8$ & $1.1 \pm 0.9$ & $1.0 \pm 0.9$ \\
\hline \multicolumn{8}{|l|}{ Resection type } \\
\hline Anatomic & 117 & 5 & 25 & 11 & 19 & 28 & 29 \\
\hline Non-anatomic & 70 & 5 & 10 & 6 & 10 & 15 & 24 \\
\hline \multicolumn{8}{|l|}{ HBV DNA } \\
\hline$\leqslant 10^{3}$ copies $\mathrm{ml}^{-1}$ & 93 & 3 & 20 & 9 & 16 & 17 & 28 \\
\hline$>10^{3}$ copies $\mathrm{ml}^{-1}$ & 40 & 2 & 12 & 3 & 3 & 11 & 9 \\
\hline \multicolumn{8}{|l|}{ AFP } \\
\hline$\leqslant 20 \mathrm{ng} \mathrm{ml}^{-1}$ & 77 & 3 & 13 & 6 & 13 & 18 & 24 \\
\hline$>20 \mathrm{ng} \mathrm{ml}^{-1}$ & 94 & 6 & 19 & 8 & 13 & 22 & 26 \\
\hline \multicolumn{8}{|c|}{ Necroinflammatory grade by HAl } \\
\hline Mean \pm s.d. & $4.8 \pm 2.1$ & $3.7 \pm 1.7$ & $4.0 \pm 1.7$ & $5.4 \pm 1.8$ & $5.4 \pm 2.4$ & $4.8 \pm 2.2$ & $5.0 \pm 2.0$ \\
\hline INR (mean \pm s.d.) & $1.1 \pm 0.3$ & $1.0 \pm 0.04$ & $1.1 \pm 0.2$ & $1.1 \pm 0.2$ & $1.1 \pm 0.1$ & $1.2 \pm 0.5$ & $1.2 \pm 0.4$ \\
\hline Platelets & 200 & 233 & 278 & 187 & 202 & 194 & 154 \\
\hline Albumin & 4.2 & 4.4 & 4.3 & 4.3 & 4 & 4.2 & 4.1 \\
\hline ALT (median) & 39 & 22 & 30 & 30 & 39 & 40 & 44 \\
\hline Bilirubin & 1.0 & 0.7 & 0.7 & 0.7 & 0.7 & 1.5 & 1.1 \\
\hline Creatinine & 1.0 & 0.9 & 0.9 & 0.8 & 1.2 & 1.0 & 1.0 \\
\hline
\end{tabular}


Table 1. (Continued)

Ishak stage

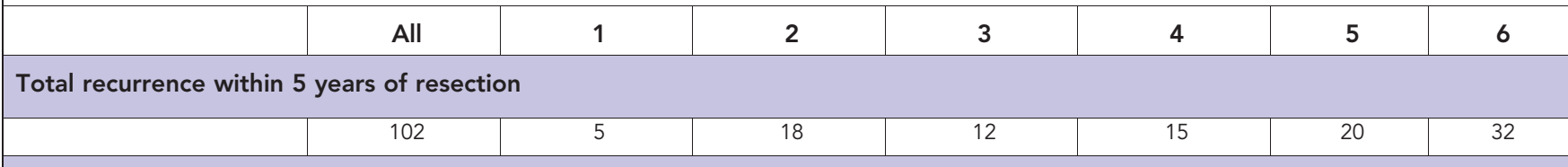

Early recurrence within 2 years of resection

\begin{tabular}{l|l|c|c|c|c|c|c|c|}
\hline & 75 & 2 & 12 & 10 & 10 & 14 & 27 \\
\hline \\
\hline
\end{tabular}

Abbreviations: AFP = alpha-fetoprotein; $\mathrm{ALT}=$ alanine transaminase; $\mathrm{HBV}=$ hepatitis $\mathrm{B}$ virus; $\mathrm{HCC}=$ hepatocellular carcinoma; INR = international normalized ratio

Table 2. Factors associated with poor overall survival or poor recurrence-free survival among all HBV-HCC patients

\begin{tabular}{|c|c|c|c|c|c|c|}
\hline & \multicolumn{3}{|c|}{ Overall survival } & \multicolumn{3}{|c|}{ Recurrence-free survival } \\
\hline & \multirow{2}{*}{$\begin{array}{c}\text { Univariate } \\
P \text {-value }\end{array}$} & \multicolumn{2}{|c|}{ Multivariate } & \multirow{2}{*}{$\begin{array}{c}\text { Univariate } \\
\boldsymbol{P} \text {-value }\end{array}$} & \multicolumn{2}{|c|}{ Multivariate } \\
\hline & & $\mathrm{HR}(95 \% \mathrm{Cl})$ & $\boldsymbol{P}$-value & & HR $(95 \% \mathrm{Cl})$ & $\boldsymbol{P}$-value \\
\hline Gender (male) & 0.02 & & & 0.04 & & \\
\hline Age $(>56)$ & 0.83 & & & 0.74 & & \\
\hline Race (Asian) & 0.003 & & & 0.07 & & \\
\hline Poorly differentiated tumour & $<0.001$ & & & 0.001 & $1.58(1.01-2.47)$ & 0.04 \\
\hline Microvascular invasion & 0.03 & & & 0.05 & & \\
\hline Macrovascular invasion & $<0.001$ & & & $<0.001$ & $6.17(2.06-18.51)$ & 0.001 \\
\hline Tumour number $>1$ & 0.40 & & & 0.68 & & \\
\hline Tumour size $(\mathrm{cm})$ & $<0.001$ & $1.17(1.09-1.26)$ & $<0.001$ & $<0.001$ & $1.08(1.04-1.13)$ & $<0.001$ \\
\hline Resection margin $(\mathrm{cm})$ & 0.04 & $1.34(1.00-1.79)$ & 0.05 & 0.33 & & \\
\hline Anatomic resection & $<0.001$ & & & 0.002 & & \\
\hline Detectable circulating HBV DNA & 0.39 & & & 0.87 & & \\
\hline $\operatorname{ALT}\left(>30\right.$ units $^{-1}$ ) & 0.001 & & & 0.02 & & \\
\hline $\operatorname{AFP}\left(>20 \mathrm{ng} \mathrm{ml}^{-1}\right)$ & 0.002 & $2.62(1.16-5.95)$ & 0.02 & 0.01 & & \\
\hline HAl grade & 0.22 & & & 0.001 & $1.22(1.09-1.36)$ & $<0.001$ \\
\hline Ishak stage 6 & 0.008 & $4.86(2.29-10.28)$ & $<0.001$ & 0.05 & $1.88(1.19-2.99)$ & 0.007 \\
\hline
\end{tabular}

patient cohort (Supplementary Tables 4 and 5). Ishak stage 6 was significantly associated with poor overall survival, recurrence-free survival and early recurrence rate in univariate and multivariate analysis, whereas Ishak 5 was not different from Ishak 1-4 in all the analyses.

Factors associated with overall survival and recurrence-free survival in non-cirrhotic (Ishak stage 1-5) and cirrhotic patients (Ishak stage 6). Among patients with Ishak stage $1-5$, only tumour size was independently associated with poor overall survival in multivariate analysis, and Ishak stage had no impact on overall survival. In addition, tumour size, serum AFP $>20 \mathrm{ng} \mathrm{ml}^{-1}$ and HAI were independently associated with poor recurrence-free survival (Table 3a) and early recurrence rate (Supplementary Table 6).

Among patients with Ishak stage 6, poorly differentiated histology and tumour size were independently associated with poor overall survival, and tumour size was independently associated with poor recurrence-free survival (Table 3b). Macrovascular invasion was independently associated with early recurrence rate (Supplementary Table 6).

The finding that serum AFP $>20 \mathrm{ng} \mathrm{ml}^{-1}$ was independently associated with poor recurrence-free survival only among patients with Ishak stage 1-5 and not those with Ishak stage 6 was further illustrated by Kaplan-Meier analysis stratified by serum AFP categories among these two groups. Serum AFP $>20 \mathrm{ng} \mathrm{ml}^{-1}$ was associated with poor overall survival, both in patients with Ishak 

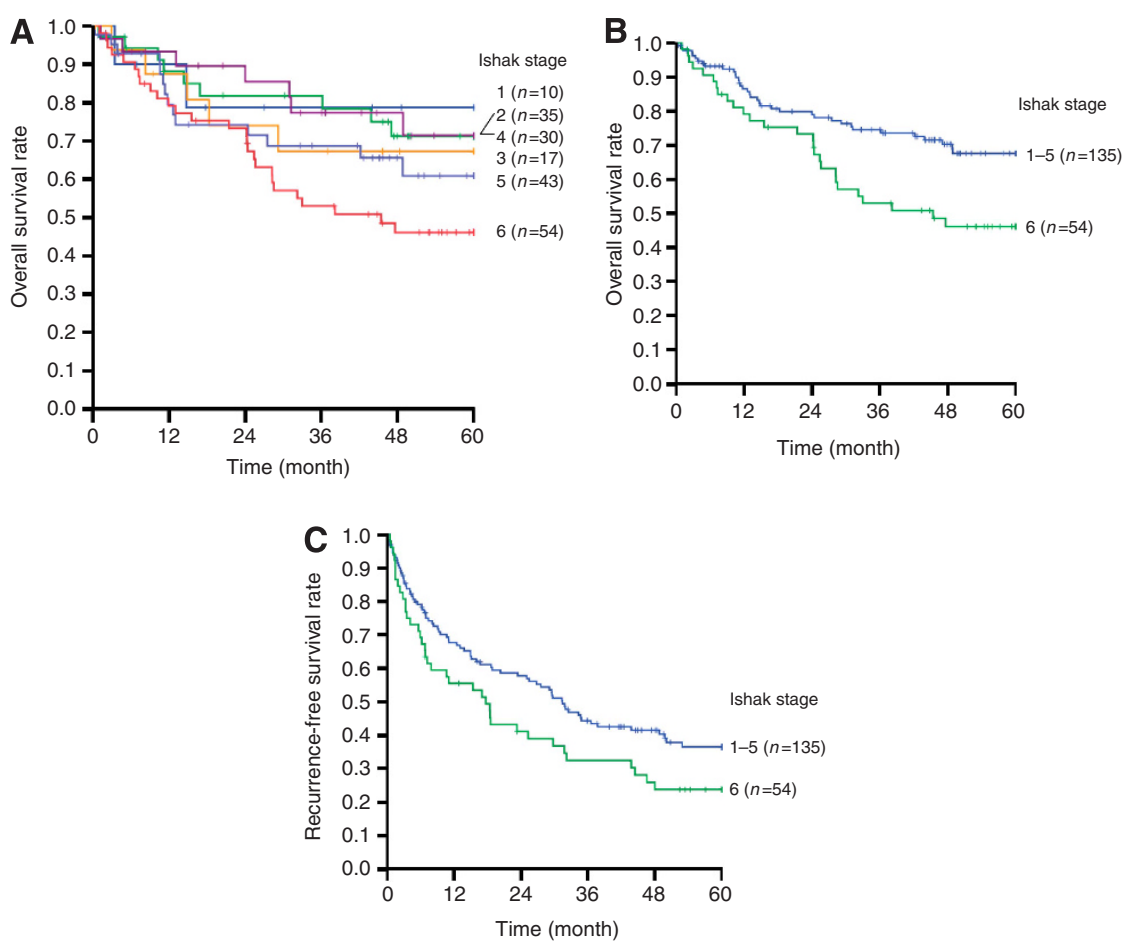

Figure 2. The impact of Ishak stage on overall and recurrence-free survival following surgical resection. Survival curves were constructed using the Kaplan-Meier method and compared using a log-rank test. (A) Overall survival curve stratified by individual Ishak stage. Among patients with Ishak stage 1-5, Ishak stage did not influence the overall survival. Navy: Ishak stage 1; green: Ishak stage 2; orange: Ishak stage 3; purple: Ishak stage 4; blue: Ishak stage 5; red: Ishak stage 6. (B) Overall survival curve stratified by Ishak stage 6 or less. Ishak stage 6 (green) had poor overall survival compared with patients with Ishak stage 1-5 (navy) $(P=0.008)$. (C) Recurrence-free survival stratified by Ishak stage 6 (green) or less (navy) $(P=0.05)$.

stage 1-5 and those with Ishak stage 6 (Figure $3 \mathrm{~A}$ ). However, while serum AFP $>20 \mathrm{ng} \mathrm{ml}^{-1}$ was associated with a higher recurrence rate among patients with Ishak stage $1-5(P=0.007)$, it had no impact on recurrence among patients with Ishak stage $6(P=0.84)$ (Figure 3B).

\section{DISCUSSION}

Although cirrhosis is a significant risk factor for HCC development, HCC arising in the non-cirrhotic liver represents a poorly defined subgroup of primary liver cancers (Bralet et al, 2000; Liu et al, 2009; Tretiakova et al, 2009, 2010; Trevisani et al, 2010). This study focused on HCC with a single aetiology, chronic HBV infection, and used surgical resection specimens to accurately score the severity of fibrosis and inflammation in the non-neoplatic liver using the modified Ishak method and HAI. The Ishak staging system was utilised because it is widely accepted for evaluating liver fibrosis in chronic liver disease and it allows for precise histologic assessment of liver fibrosis; more stages of fibrosis (0-6) are defined by other staging systems (such as the Scheuer system which only includes 4 stages). The Ishak score also uniquely allows for distinction between early, incomplete cirrhosis (stage 5) vs established cirrhosis (stage 6). Emphasis was placed on consistent histopathologic evaluation, and all specimens were scored by a single liver pathologist, who was blinded to clinical outcomes. No data on liver fibrosis or cirrhosis were extracted from clinical pathology reports for the purposes of this study.

An important and novel finding of this study is that progressive increases in fibrosis stage are not associated with progressive decrease in survival or recurrence-free survival among HBV-HCC resection patients until complete cirrhosis is established (stage 6).
Surprisingly, the distinction between early, incomplete cirrhosis (stage 5) and established cirrhosis (stage 6) is associated with significant impact on prognosis. The association of liver fibrosis with prognosis following surgical resection is a clinically relevant question that has been evaluated in several studies (Ko et al, 2002; Wayne et al, 2002; Pawlik et al, 2005; Wu et al, 2009; Gassmann et al, 2010; Hung et al, 2010). Hepatocellular carcinomas with mixed underlying aetiology were often analysed together and were therefore associated with more severe liver fibrosis (Gassmann et al, 2010). In addition, most of these studies combined Ishak stage 5 and Ishak stage 6 as one entity, and the combined Ishak stage $5 / 6$ is associated with poor survival in some studies but not others (Wu et al, 2009; Gassmann et al, 2010). Our data may therefore provide an explanation to reconcile these discrepancies. Ishak stage 6 is not only associated with poor overall survival, but also poor recurrence-free survival and early recurrence rate. Moreover, different prognostic factors are associated with recurrence events among Ishak stage 1-5 patients $v s$ Ishak 6 patients: for example, AFP $>20 \mathrm{ng} \mathrm{ml}^{-1}$ is associated with poor recurrence-free survival only among Ishak 1-5 patients, but not among Ishak 6 patients. Although existing publications indicate that markedly elevated serum AFP is a poor prognostic indicator for HCC (Nomura et al, 1989; Peng et al, 2004), few have examined the prognostic impact of AFP in HCC associated with different fibrosis stage. Our data certainly provide strong rationale for future studies to mechanistically define the interaction between HCC and the underlying liver fibrosis in recurrence.

The single-institution cohort of 189 HCC patients included in this analysis consisted of a heterogeneous population of chronic HBV patients. Documented hepatitis B anti-viral therapy had been initiated for 141 patients peri-operatively. As such, this report cannot be interpreted as a longitudinal study for HBV. However, the independent impact of Ishak stage 6 on prognosis is still 
Table 3. Univariate and multivariate analysis of factors associated with poor overall survival or poor recurrence-free survival in patients with Ishak stage 1-5 (a) and Ishak stage 6 (b)

\begin{tabular}{|c|c|c|c|c|c|c|}
\hline & \multicolumn{3}{|c|}{ Overall survival } & \multicolumn{3}{|c|}{ Recurrence-free survival } \\
\hline & \multirow{2}{*}{$\begin{array}{c}\text { Univariate } \\
\boldsymbol{P} \text {-value }\end{array}$} & \multicolumn{2}{|c|}{ Multivariate } & \multirow{2}{*}{$\begin{array}{c}\text { Univariate } \\
\boldsymbol{P} \text {-value }\end{array}$} & \multicolumn{2}{|c|}{ Multivariate } \\
\hline & & $\mathrm{HR}(95 \% \mathrm{Cl})$ & $\boldsymbol{P}$-value & & $\mathrm{HR}(95 \% \mathrm{Cl})$ & $P$-value \\
\hline \multicolumn{7}{|l|}{ (a) } \\
\hline $\begin{array}{l}\text { Gender (male) } \\
\text { Age (>56) } \\
\text { Race (Asian) } \\
\text { Poorly differentiated tumour } \\
\text { Microvascular invasion } \\
\text { Macrovascular invasion } \\
\text { Tumour number }>1 \\
\text { Tumour size }(\mathrm{cm}) \\
\text { Resection margin } \\
\text { Detectable circulating HBV DNA } \\
\text { ALT }\left(>30 \text { units }^{-1}\right) \\
\text { AFP }\left(>20 \mathrm{ng} \mathrm{ml}^{-1}\right) \\
\text { HAI grade } \\
\text { Ishak stage }\end{array}$ & $\begin{array}{l}0.10 \\
0.63 \\
0.13 \\
0.005 \\
0.34 \\
0.21 \\
0.84 \\
0.001 \\
0.011 \\
0.17 \\
0.002 \\
0.02 \\
0.32 \\
0.38\end{array}$ & $1.16(1.06-1.26)$ & 0.001 & $\begin{array}{l}0.18 \\
0.91 \\
0.62 \\
0.018 \\
0.027 \\
0.009 \\
0.62 \\
<0.001 \\
0.54 \\
0.71 \\
0.039 \\
0.014 \\
0.004 \\
0.99\end{array}$ & $\begin{array}{l}1.10(1.04-1.16) \\
1.85(1.08-3.18) \\
1.20(1.06-1.37)\end{array}$ & $<0.001$ \\
\hline \multicolumn{7}{|l|}{ (b) } \\
\hline $\begin{array}{l}\text { Gender (male) } \\
\text { Age }(>56) \\
\text { Race (Asian) } \\
\text { Poorly differentiated tumour } \\
\text { Microvascular invasion } \\
\text { Macrovascular invasion } \\
\text { Tumour number }>1 \\
\text { Tumour size }(\mathrm{cm}) \\
\text { Resection margin } \\
\text { Detectable circulating HBV DNA } \\
\text { ALT ( }>30 \text { units } I^{-1} \text { ) } \\
\text { AFP }\left(>20 \mathrm{ng} \mathrm{ml}^{-1} \text { ) }\right. \\
\text { HAl grade }\end{array}$ & $\begin{array}{c}0.25 \\
0.29 \\
0.028 \\
0.003 \\
0.02 \\
<0.001 \\
0.26 \\
0.002 \\
0.56 \\
0.85 \\
0.32 \\
0.02 \\
0.66\end{array}$ & $\begin{array}{l}3.20(1.27-8.05) \\
1.16(1.04-1.29)\end{array}$ & 0.01 & $\begin{array}{c}0.17 \\
0.97 \\
0.05 \\
0.026 \\
0.70 \\
<0.001 \\
0.97 \\
0.013 \\
0.31 \\
0.85 \\
0.42 \\
0.32 \\
0.20\end{array}$ & $1.14(1.03-1.26)$ & 0.01 \\
\hline
\end{tabular}

significant in these 141 patients. These data therefore highlight the importance of treating underlying hepatitis B in patients at risk for HBV-HCC; in addition to lowering the likelihood of future de novo tumour development (by viral suppression), the reduction in fibrosis that results from anti-viral therapy may also lead to improved survival following treatment of HCC with curative intent (Osakabe et al, 2011; Kurokawa et al, 2012).

No single patient in our cohort exhibited absolutely 'normal liver,' with an Ishak stage of 0 . A direct oncogenic role for HBV has been proposed, which may occur in the absence of cirrhosis or even moderate fibrosis (Bralet et al, 2000; Farazi and DePinho, 2006). Genomic integration of HBV into the host genome can result in genetic alterations, such as chromosomal rearrangements as well as activation of cellular oncogenes or inactivation of tumour suppressor genes. In addition, viral proteins such as HBV X protein can influence intracellular signal transduction pathways and alter host gene expression, contributing to malignant transformation of chronically infected hepatocytes (Farazi and DePinho, 2006; Chemin and Zoulim, 2009). Indeed high HBV viral load is an independent predictor of HCC development in both cirrhotic and non-cirrhotic patients (Liu et al, 2006; Wu et al, 2008; Sung et al, 2009).

Our data suggest that cirrhosis is associated with more frequent HCC recurrence. Tumour-related factors are associated with early recurrence, whereas high viral load and HAI are associated with late recurrence among HBV-HCC patients who had not received anti-viral therapy (Imamura et al, 2003; Wu et al, 2009). Our data indeed confirmed that tumour-associated factors (tumour size and macrovascular invasion) have a significant impact on early recurrence. Surprisingly, Ishak stage 6 is also independently associated with early recurrence. Although several studies suggested that early HCC recurrence may result from intrahepatic metastasis of the original tumour, whereas late HCC recurrence showed different clonal origins and may reflect de novo formation of secondary HCC (Chen et al, 2000; Imamura et al, 2003; Wu et al, 2009); future studies identifying molecular signatures in primary as well as recurred-HCC associated with cirrhotic and non-cirrhotic livers are necessary to understand whether and how liver fibrosis stage influences the metastatic behaviour of HCC as well as de novo HCC formation. It would also be very interesting to identify the impact of Ishak stage on late-recurrence events in future studies as these patients continue to be followed.

There are several inherent limitations of this study. Although there were 30-60 patients in most Ishak stages, our study may be limited by the patient sample size in Ishak stage 1-5, especially for Ishak stage 1 and 3 . It is possible that if there were more patients available within these early stages, we may have been able to observe a difference in outcomes in patients with minimal or moderate fibrosis. However, this would probably not change the observation that Ishak stage 6 is associated with the worst outcome. 

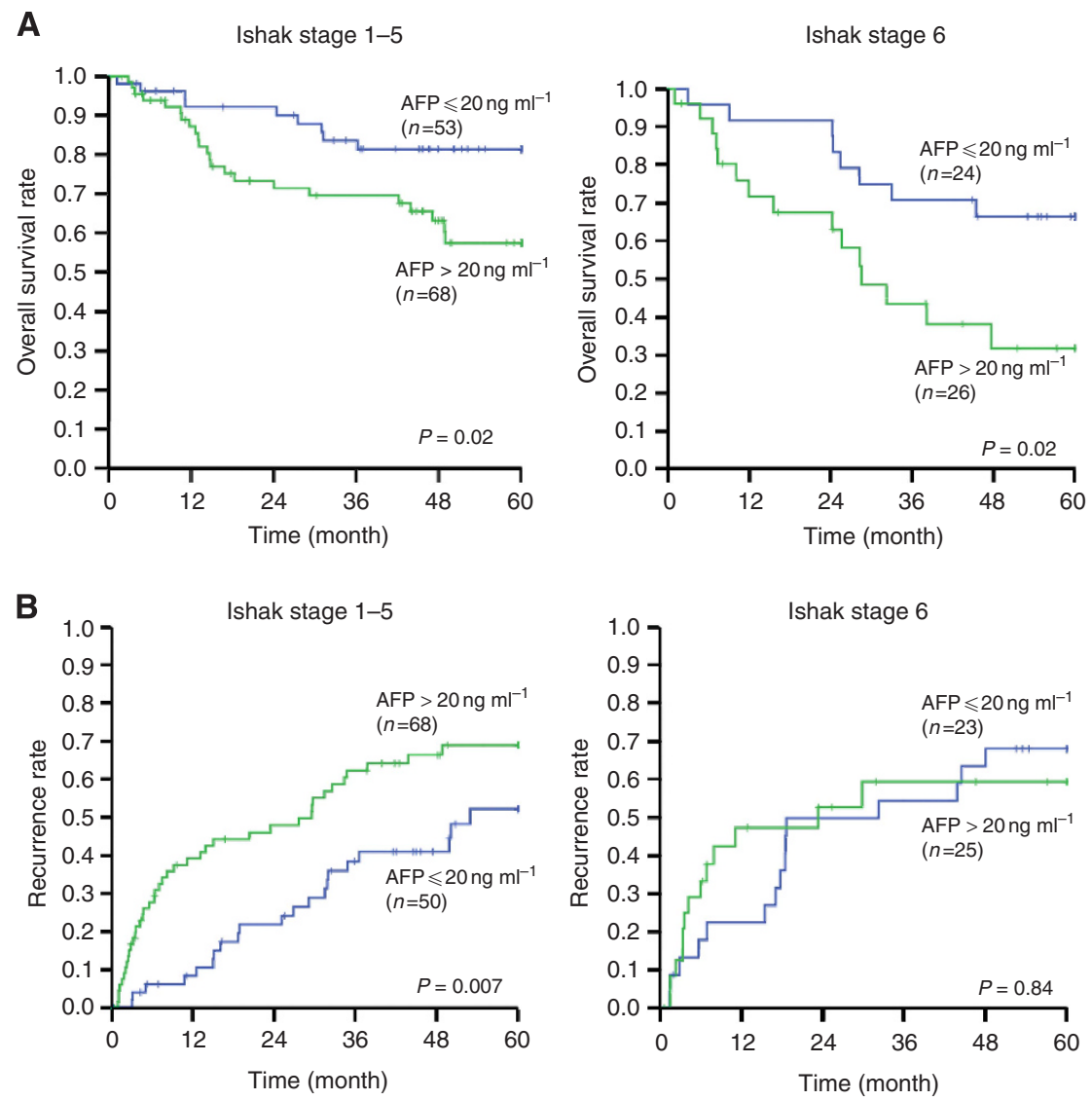

Figure 3. Serum AFP $>20 \mathrm{ng} \mathrm{ml}^{-1}$ was associated with poor recurrence among patients with Ishak stage 1-5, but not among those with Ishak stage 6. Overall survival curve (A) or recurrence curve (B) stratified by serum AFP category for patients with Ishak stage 1-5 or those with Ishak stage 6 was constructed using the Kaplan-Meier method and compared using a log-rank test.

A salient observation in our data set is the difference in survival seen among patients with Ishak stage 5 vs 6 fibrosis, which are histologically similar and have sometimes been grouped together in prior reports. Precisely differentiating Ishak stage 5 from stage 6 fibrosis without the benefit of a surgical resection specimen is difficult, even with a core needle liver biopsy, as a broad survey of the liver architecture is needed in assessing the presence of complete nodules. Further efforts to identify panels of serum biomarkers, or other non-invasive diagnostics that can precisely predict subtle differences in liver fibrosis may prove very helpful. A recent study has demonstrated that aspartate aminotransferaseplatelet ratio index may discriminate minimal fibrosis (Ishak stage 0 or 1) from more advanced fibrosis (Hung et al, 2010). Our data certainly support the need for additional non-invasive means in assessing minimal differences in liver fibrosis, as such subtle differences in histology are known to have significant implications on HCC patients undergoing surgical resection.

In summary, HBV-HCC patients with Ishak stage 6 have poor overall and recurrence-free survival after surgical resection, when compared with patients with Ishak stage 1-5; however, among the latter group, progressive increase in Ishak stage from stage 1 to stage 5 is not associated with poor overall survival and recurrencefree survival. This information may lead to more effective treatment algorithms for patients with HBV-HCC, and may assist in optimal selection of patients for liver resection.

\section{ACKNOWLEDGEMENTS}

This work was supported by a research grant from Gilead Sciences.

\section{CONFLICT OF INTEREST}

The authors declare no conflict of interest.

\section{REFERENCES}

Bralet M-P, Régimbeau J-M, Pineau P, Dubois S, Loas G, Degos F, Valla D, Belghiti J, Degott C, Terris B (2000) Hepatocellular carcinoma occurring in nonfibrotic liver: epidemiologic and histopathologic analysis of 80 french cases. Hepatology 32: 200-204.

Brunt EM (2000) Grading and staging the histopathological lesions of chronic hepatitis: the Knodell histology activity index and beyond. Hepatology 31: 241-246.

Chemin I, Zoulim F (2009) Hepatitis B virus induced hepatocellular carcinoma. Cancer Lett 286: 52-59.

Chen C-J, Yang H-I, Su J, Jen C-L, You S-L, Lu S-N, Huang G-T, Iloeje UH. Group ftR-HS (2006) Risk of hepatocellular carcinoma across a biological gradient of serum hepatitis B virus DNA level. JAMA 295: 65-73.

Chen Y-J, Yeh S-H, Chen J-T, Wu C-C, Hsu M-T, Tsai S-F, Chen P-J, Lin C-H (2000) Chromosomal changes and clonality relationship between primary and recurrent hepatocellular carcinoma. Gastroenterology 119: 431-440.

de Lope CR, Tremosini S, Forner A, Reig M, Bruix J (2012) Management of HCC. J Hepatol 56(Suppl 1): S75-S87.

El-Serag HB (2011) Hepatocellular Carcinoma. N Engl J Med 365: 1118-1127. European Association for the Study of the L, European Organisation for R, Treatment of C (2012) EASL-EORTC clinical practice guidelines: management of hepatocellular carcinoma. J Hepatol 56: 908-943.

Farazi PA, DePinho RA (2006) Hepatocellular carcinoma pathogenesis: from genes to environment. Nat Rev Cancer 6: 674-687.

Gassmann P, Spieker T, Haier J, Schmidt F, Mardin WA, Senninger N (2010) Prognostic impact of underlying liver fibrosis and cirrhosis after 
curative resection of hepatocellular carcinoma. World J Surg 34: 2442-2451.

Goodman ZD (2007) Grading and staging systems for inflammation and fibrosis in chronic liver diseases. J Hepatol 47: 598-607.

Hung H-H, Su C-W, Lai C-R, Chau G-Y, Chan C-C, Huang Y-H, Huo T-I, Lee P-C, Kao W-Y, Lee S-D, Wu J-C (2010) Fibrosis and AST to platelet ratio index predict post-operative prognosis for solitary small hepatitis B-related hepatocellular carcinoma. Hepatol Int 4: 691-699.

Imamura H, Matsuyama Y, Tanaka E, Ohkubo T, Hasegawa K, Miyagawa S, Sugawara Y, Minagawa M, Takayama T, Kawasaki S, Makuuchi M (2003) Risk factors contributing to early and late phase intrahepatic recurrence of hepatocellular carcinoma after hepatectomy. J Hepatol 38: 200-207.

Ishak K, Baptista A, Bianchi L, Callea F, De Groote J, Gudat F, Denk H, Desmet V, Korb G, MacSween RNM, Phillips MJ, Portmann BG, Poulsen H, Scheuer PJ, Schmid M, Thaler H (1995) Histological grading and staging of chronic hepatitis. J Hepatol 22: 696-699.

Ko S, Kanehiro H, Hisanaga M, Nagao M, Ikeda N, Nakajima Y (2002) Liver fibrosis increases the risk of intrahepatic recurrence after hepatectomy for hepatocellular carcinoma. Br J Surg 89: 57-62.

Kurokawa M, Hiramatsu N, Oze T, Yakushijin T, Miyazaki M, Hosui A, Miyagi T, Yoshida Y, Ishida H, Tatsumi T, Kiso S, Kanto T, Kasahara A, Iio S, Doi Y, Yamada A, Oshita M, Kaneko A, Mochizuki K, Hagiwara H, Mita E, Ito T, Inui Y, Katayama K, Yoshihara H, Imai Y, Hayashi E, Hayashi N, Takehara T (2012) Long-term effect of lamivudine treatment on the incidence of hepatocellular carcinoma in patients with hepatitis B virus infection. J Gastroenterol 47: 577-585.

Liu C-J, Chen B-F, Chen P-J, Lai M-Y, Huang W-L, Kao J-H, Chen D-S (2006) Role of hepatitis B virus precore/core promoter mutations and serum viral load on noncirrhotic hepatocellular carcinoma: a case-control study. J Infect Dis 194: 594-599.

Liu S, Zhang H, Gu C, Yin J, He Y, Xie J, Cao G (2009) Associations between hepatitis B virus mutations and the risk of hepatocellular carcinoma: a meta-analysis. J Natl Cancer Inst 101: 1066-1082.

Lok ASF, McMahon BJ (2009) Chronic hepatitis B: update 2009. Hepatology 50: 661-662.

Nomura F, Ohnishi K, Tanabe Y (1989) Clinical features and prognosis of hepatocellular carcinoma with reference to serum alpha-fetoprotein levels. Analysis of 606 patients. Cancer 64: 1700-1707.

Osakabe K, Ichino N, Nishikawa T, Sugiyama H, Kato M, Kitahara S, Hashimoto S, Kawabe N, Harata M, Nitta Y, Murao M, Nakano T, Shimazaki H, Arima Y, Suzuki K, Yoshioka K (2011) Reduction of liver stiffness by antiviral therapy in chronic hepatitis B. J Gastroenterol 46: $1324-1334$
Pawlik TM, Poon RT, Abdalla EK, Zorzi D, Ikai I, Curley SA, Nagorney DM, Belghiti J, Ng IO, Yamaoka Y, Lauwers GY, Vauthey JN. International Cooperative Study Group on Hepatocellular Carcinoma (2005) Critical appraisal of the clinical and pathologic predictors of survival after resection of large hepatocellular carcinoma. Arch Surg 140: 450-458.

Peng S-Y, Chen WJ, Lai P-L, Jeng Y-M, Sheu J-C, Hsu H-C (2004) High $\alpha$-fetoprotein level correlates with high stage, early recurrence and poor prognosis of hepatocellular carcinoma: significance of hepatitis virus infection, age, p53 and $\beta$-catenin mutations. Int J Cancer 112: 44-50.

Sung F-Y, Jung C-M, Wu C-F, Lin C-L, Liu C-J, Liaw Y-F, Tsai K-S, Yu M-W (2009) Hepatitis B virus core variants modify natural course of viral infection and hepatocellular carcinoma progression. Gastroenterology 137: 1687-1697.

Tretiakova MS, Hart J, Shabani-Rad MT, Zhang J, Gao Z-h (2009) Distinction of hepatocellular adenoma from hepatocellular carcinoma with and without cirrhosis using E-cadherin and matrix metalloproteinase immunohistochemistry. Mod Pathol 22: 1113-1120.

Tretiakova MS, Shabani-Rad MT, Guggisberg K, Hart J, Anders RA, Gao Z-h (2010) Genomic and immunophenotypical differences between hepatocellular carcinoma with and without cirrhosis. Histopathology 56: 683-693.

Trevisani F, Frigerio M, Santi V, Grignaschi A, Bernardi M (2010) Hepatocellular carcinoma in non-cirrhotic liver: a reappraisal Dig Liver Dis 42: 341-347.

Wayne JD, Lauwers GY, Ikai I, Doherty DA, Belghiti J, Yamaoka Y, Regimbeau JM, Nagorney DM, Do KA, Ellis LM, Curley SA, Pollock RE, Vauthey JN (2002) Preoperative predictors of survival after resection of small hepatocellular carcinomas. Ann Surg 235: 722-730.

Wu C-F, Yu M-W, Lin C-L, Liu C-J, Shih W-L, Tsai K-S, Chen C-J (2008) Long-term tracking of hepatitis B viral load and the relationship with risk for hepatocellular carcinoma in men. Carcinogenesis 29: 106-112.

Wu J-C, Huang Y-H, Chau G-Y, Su C-W, Lai C-R, Lee P-C, Huo T-I, Sheen IJ, Lee S-D, Lui W-Y (2009) Risk factors for early and late recurrence in hepatitis B-related hepatocellular carcinoma. J Hepatol 51: 890-897.

Yang JD, Kim WR, Coelho R, Mettler TA, Benson JT, Sanderson SO, Therneau TM, Kim B, Roberts LR (2011) Cirrhosis is present in most patients with hepatitis B and hepatocellular carcinoma. Clin Gastroenterol Hepatol 9: 64-70.

This work is published under the standard license to publish agreement. After 12 months the work will become freely available and the license terms will switch to a Creative Commons AttributionNonCommercial-Share Alike 3.0 Unported License.

Supplementary Information accompanies this paper on British Journal of Cancer website (http://www.nature.com/bjc) 